\title{
Efficiency Improvement of Agricultural Winch Machines
}

\author{
Martin Kodrič 1 - Jože Flašker ${ }^{2}$ - Stanislav Pehan ${ }^{2}$ \\ 1 Krško Nuclear Power Plant, Slovenia \\ 2 University of Maribor, Faculty for Mechanical Engineering, Slovenia
}

In this article the problems with the use of the common winch cart on very steep terrain planted with permanent crops are described, especially with regard to energy losses. A hypothesis is developed regarding the improved use of the potential energy that leads to the development of a new economical hydraulic machine. A transmission of the new agricultural tractor that can use the much bigger share of the effective potential energy is conceived in rough principles. A portable flatbed improves the total efficiency. A comparable analysis on very different sloped terrains is presented to argue for the greater efficiency of the new machine. The yearly fuel quantity saving by using the new hydraulic machine on the sloping terrain with realistic topography is $36 \%$ in comparison to the winch cart. Decisional limits about the minimum internal combustion engine power are discussed.

Keywords: sloped terrain, permanent crop treatments, hydraulic tractor, crop treatment efficiency

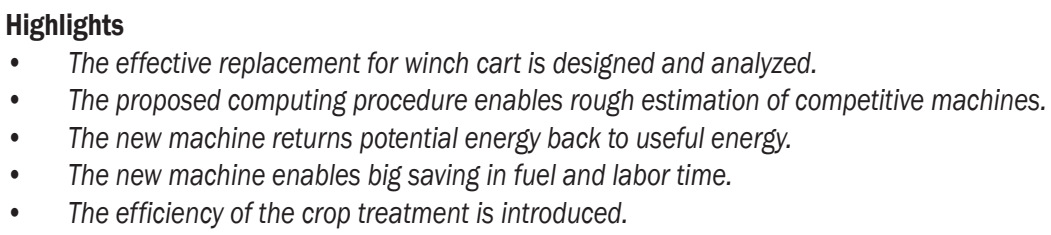

\section{INTRODUCTION}

To treat the agriculture terrain planted with permanent crops and inclined at angles greater than $60 \%$ winch power is required. Working on such terrain with conventional agriculture tractors, even equipped with caterpillar treads, is a dangerous venture and is often impossible due to the weak traction forces on the sloped terrain (slip). Working on steep inclines with ordinary tractors frequently results in accidents [1]. Treatment of the permanent crops on the sloped terrain requires about twenty-four executions per year.

In recent years, many comprehensive studies about treating slope agriculture terrains have been made [2] to [4]. Probably the most influential one is by a German author [5] who determined the basic limits of the usability of different agricultural tractors and machines; this is considered to be the base understanding, Fig. 1.

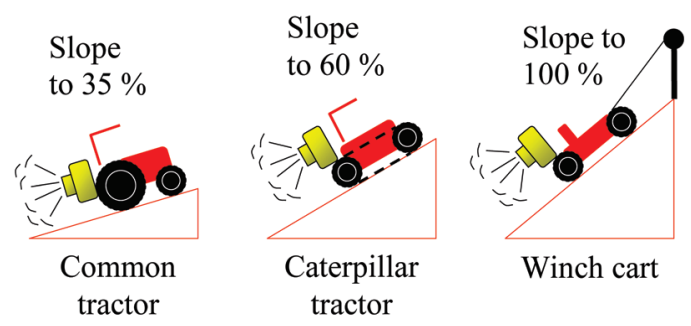

Fig. 1. Limits of terrain slope about using of proper agriculture tractor or machine
The usage of tractors and agricultural machinery on slopes with different inclines is described in the references [6] to [8]. The great issue with ordinary tractors is their stability when working on steep terrain [9].

The current machine considered appropriate for agiculture treatment on a very sloped terrain is a cart driven by the winch that is firmly placed on the top of the slope. Such a cart has its own engine for powering accessories. The winch located on the flat reef can be driven by a tractor propeller shaft or has its own engine. When the cart is sliding downwards on the slope, only one accessory can be active. Afterwards, with the rope anchored on the flat reef, the cart is pulled upwards. In this stroke, all accessories are switched off, Fig. 2. Consequently, this type of treatment leads to long processing time and is significantly more expensive than the treatments on the flatter terrains. The treatment time is often decisive [10] and [11].

Special care should be devoted to the enormous amount of energy consumed. In addition to higher fuel costs, there are also greater $\mathrm{CO}_{2}$ emissions and higher expenses for harvesting in general. Consequently, farmers who use the described technology cannot be competitive on the market. The focus of this paper is to indicate the basic problems of current technology for treating sloped terrains and to show ways to solve them in order to reduce energy and labour costs. 


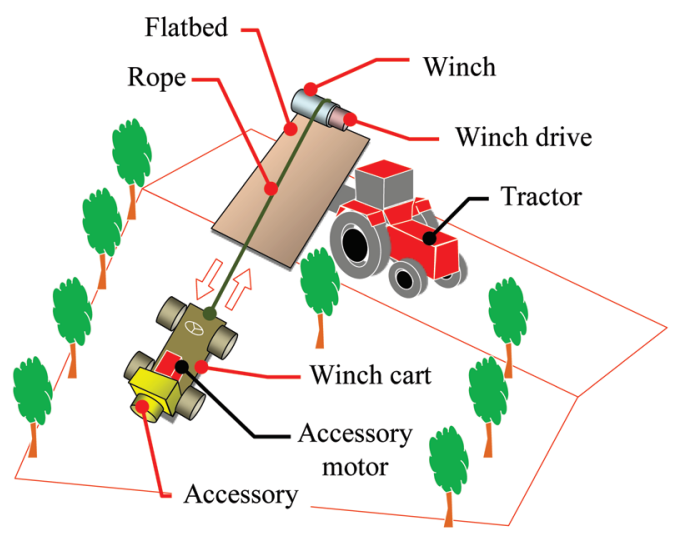

Fig. 2. Basic working principle by using winch cart

\section{THE ENERGY LOSSES FOR THE TREATMENT OF FLAT AND SLOPED TERRAINS}

For the winch cart, the first energy loss is the one that occurs due to not using potential energy during the downward stroke of the winch cart. The second energy loss is inherent to the basic working principle in which it is evident that one of two strokes is useless for using the accessories. Under the assumption that the downward stroke is the working stroke for the accessories, the upward stroke is a waste of time and energy. The upward stroke should be performed to reposition the winch cart on the top of the slope, along the flat reef, to make a longitudinal relocation of the cart, Fig. 3.

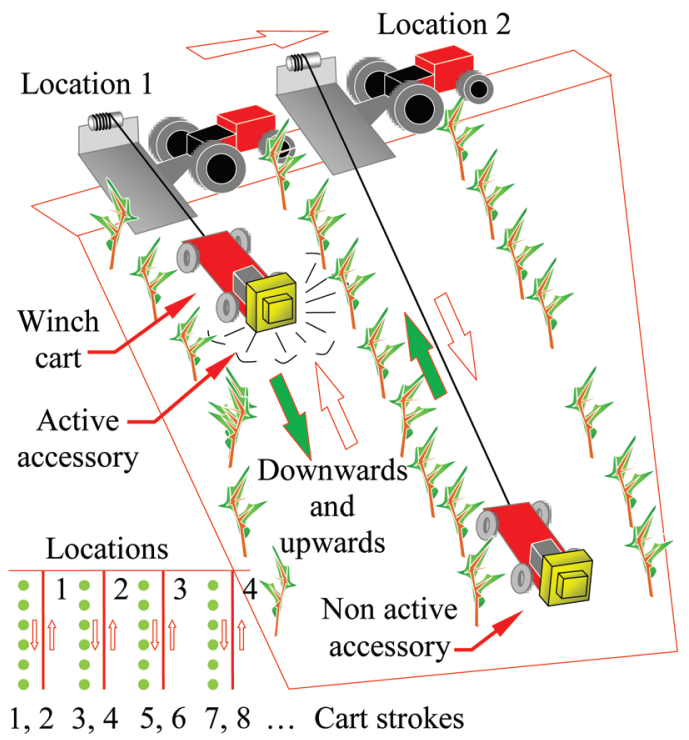

Fig. 3. Basic treatment principle on terrains inclined more than $60 \%$
The working principle of the treatment (probably of the same crops) by using a common agricultural tractor on the terrains sloped less than $60 \%$ is much more rational [12]. Each part of the tractor path is maximally effective with all accessories fully active all the time, Fig. 4.

To illustrate the problem of excessive energy consumption on sloped agricultural terrain, a few different cases are carried out. The energy needed for the movement on varied terrain inclined by $0 \%, 35 \%$, $60 \%$ and $100 \%$ are compared, Table 1 . The length of the machine path is 100 metres. To obtain comparable data, all relevant vehicles characteristics are identical, including vehicles mass, rolling resistance and moving velocities. The vehicles characteristics correspond to the average tractors [2].

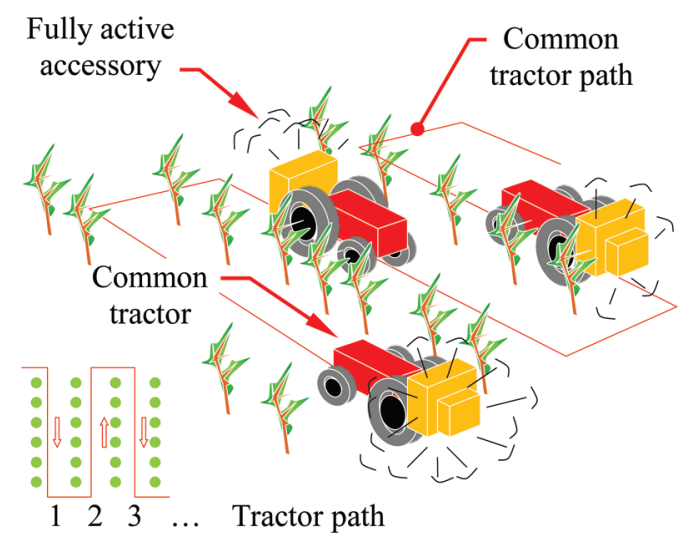

Fig. 4. Basic treatment principle on terrains inclined less than $60 \%$

Table 1. Data for the movement the machine equipped with the mower in one stroke (upwards)

\begin{tabular}{lcccc}
\hline Machine & $\begin{array}{c}\text { Common or caterpillar } \\
\text { tractor }\end{array}$ & $\begin{array}{c}\text { Winch } \\
\text { cart }\end{array}$ \\
\hline Terrain slope [\%] & 0 & 35 & 60 & 100 \\
\hline Energy for climbing up [MJ] & 0.48 & 1.00 & 1.31 & 1.71 \\
\hline Power for climbing up [kW] & 6 & 11 & 15 & 19 \\
\hline Potential energy [MJ] & 0 & 0.04 & 0.28 & 0.63 \\
\hline Potential power [kW] & 0 & 0.5 & 3 & 7 \\
\hline
\end{tabular}

The data in the Table 1 are calculated according to the Eqs. (1) to (7).

$$
\begin{gathered}
R_{f}=f_{r} \cdot m \cdot \cos \alpha \cdot g, \\
R_{S}=m \cdot \sin \alpha \cdot g .
\end{gathered}
$$

where $R_{f}$ is rolling resistance, $R_{S}$ is slope resistance, $\alpha$ is terrain slope, $m$ is a total mas of tractor or cart equipped with accessories and with driver $\left(m_{T}=1300\right.$ $\mathrm{kg}$ is tractor or winch cart net weight [2], $m_{D}=85 \mathrm{~kg}$ 
is driver weight, $m_{m u}=105 \mathrm{~kg}$ is mower weight [13]) and $f_{r}=0.25$ is rolling resistance coefficient [14].

For $R_{u p}$ and $R_{\text {down }}$ see Eqs. (13) and (14).

$$
\begin{gathered}
W_{u p}=R_{u p} \cdot s, \\
W_{\text {down }}=R_{\text {down }} \cdot s, \\
P_{u p}=\frac{W_{u p}}{t}, \\
P_{\text {down }}=\frac{W_{\text {down }}}{t}, \\
t=\frac{s}{v_{a v}},
\end{gathered}
$$

where $W_{u p}$ is energy for climbing up, $W_{\text {down }}$ potential energy, $P_{u p}$ power for climbing up, $P_{\text {down }}$ potential power, $t$ labour time, $v_{a v}=4 \mathrm{~km} / \mathrm{h}$ average tractor speed [15] and $s$ length of the path.

When analysing the data gathered in Table 1, it is evident that the slope resistance is the most significant factor. To overcome the slope and rolling resistance, a winch cart needs only 3.5 times greater energy in comparison to the same vehicle moving on the flat terrain. It is also significant that potential energy theoretically rises with the terrain slope, but in fact remains unused. No winch cart currently on the market uses this potential energy.

The energy needed for treating the flat and sloped terrain are calculated (Table 2). The length of the crop line is 100 metres. The first accessory is the rotary mower; the second is the sprayer. With the use of the winch cart, the number of the strokes are doubled in comparison to the common tractor.

Table 2. Data for the treatment two columns of crops on different sloped terrains by using two accessories separately

\begin{tabular}{lcccc}
\hline Machine & \multicolumn{3}{c}{$\begin{array}{c}\text { Common or } \\
\text { caterpillar tractor }\end{array}$} & $\begin{array}{c}\text { Winch } \\
\text { cart }\end{array}$ \\
\hline Terrain slope [\%] & 0 & 35 & 60 & 100 \\
\hline Energy for treating [MJ] & 5.10 & 7.00 & 7.30 & 10.00 \\
\hline Fuel [l] & 0.42 & 0.58 & 0.61 & 0.83 \\
\hline Efficiency [\%] & 62 & 46 & 43 & 32 \\
\hline Labour time [h] & 0.1 & 0.1 & 0.1 & 0.2 \\
\hline
\end{tabular}

$m_{S p}=85 \mathrm{~kg}$; sprayer weight [13], $P_{M}=12 \mathrm{~kW}$; mower power [13] and $P_{S p}=6 \mathrm{~kW}$; sprayer power [13].

To obtain comparable results as presented in Table 2, the main characteristics of agricultural machines are the same; the same are also valid for the accessories. The enormous amount of energy needed for running accessories on the sloped terrain is a matter of concern, as is the fact that it takes twice as much time to do the work.

In Table 3, the results for the treatment of one hectare of crops per year are presented. The same shape of the field with the same number of crop lines is assumed. The machines have the same weight, and they are equipped with the same accessories.

\begin{tabular}{|c|c|c|c|c|}
\hline \multirow{2}{*}{$\begin{array}{l}\text { Machine } \\
\text { Terrain slope [\%] }\end{array}$} & \multicolumn{3}{|c|}{$\begin{array}{c}\text { Common or } \\
\text { caterpillar tractor }\end{array}$} & \multirow{2}{*}{$\begin{array}{c}\begin{array}{c}\text { Winch } \\
\text { cart }\end{array} \\
100 \\
\end{array}$} \\
\hline & 0 & 35 & 60 & \\
\hline Energy for treating [MJ] & 1458 & 1488 & 1535 & 2971 \\
\hline Fuel [l] & 121 & 123 & 127 & 247 \\
\hline $\mathrm{CO}_{2}$ emission $[\mathrm{kg}]$ & 313 & 319 & 329 & 651 \\
\hline Labour time [h] & 30 & 30 & 30 & 60 \\
\hline Efficiency [\%] & 62 & 61 & 59 & 30 \\
\hline
\end{tabular}

The data in Tables 2 and 3 are calculated by using the Eqs. (1) to (4), Eqs. (8) to (10), (13), (14) and (17).

Table 3. Data for treating one hectare of agricultural terrain per year with all accessories for tractors and winch cart

$P_{M s p}=5 \mathrm{~kW}$; manure spreader power [16], $P_{\text {SideCt }}=9 \mathrm{~kW}$; side cutter power [17], $P_{S C t}=9 \mathrm{~kW}$; spring cutter power [18], $m_{M s p}=180 \mathrm{~kg}$; manure spreader weight [16], $m_{\text {SideCt }}=170 \mathrm{~kg}$; side cutter weight [17], $m_{S C t}=170 \mathrm{~kg}$; spring cutter weight [18], and $m_{\text {Cont }}=150 \mathrm{~kg}$; and container for harvest weight.

In one year, 24 treatments of the terrain should be done: ten times with the mower, ten times with the sprayer, and once per year with all other accessories. The steepest terrain is treated with the winch cart technology; the other terrains are treated with common agriculture tractors. The results from Table 3 again show that the enormous energy consumption on the steep terrains.

\section{ECONOMICAL HYDRAULIC MACHINE CONCEIVING}

From the presented rough energy and labour time consumption analysis, it is obvious that a great opportunity exists for efficiency improvements of the winch cart. To make a step forward, an entirely new product, a new economical hydraulic (EH) machine, for treating the most difficult terrains, is conceived, designed, and made in a prototype version. The machine's design and operating method lend themselves to reducing treatment costs [19]. The energy transformation takes into account the proven design [20]. The most obvious characteristic of the new EH machine is its drive: a purely conventional internal combustion (IC) diesel engine adapted to the inclination of the terrain by its free tilting, which ensures adequate lubrication. The IC engine runs a hydraulic pump that is connected by hydraulic 
piping with hydraulic motors on wheels, winch, and accessories. The power transmission from the winch to the hydraulics pump is designed according to the already proven rules [21] and [22] and general procedures of design [23]. All hydraulic motors are controlled by a central control unit, Fig. 5. The IC engine is designed to give the minimum necessary power needed for the sloped terrain treatment. This enables the minimal dimensions and lowest weight of the new EH machine. Weight is reduced to the lower strength limit where the machine still operates [24] and [25]. When this machine is lowered down the slope the potential energy is converted into the mechanical energy for the accessories. Consequently, two accessories can be connected to the machine instead of one.

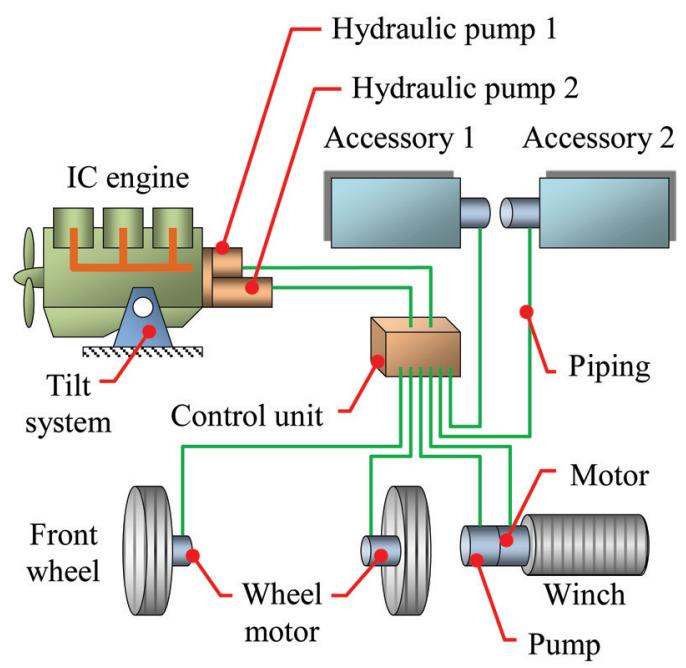

Fig. 5. Hydraulic components of the modest tractor

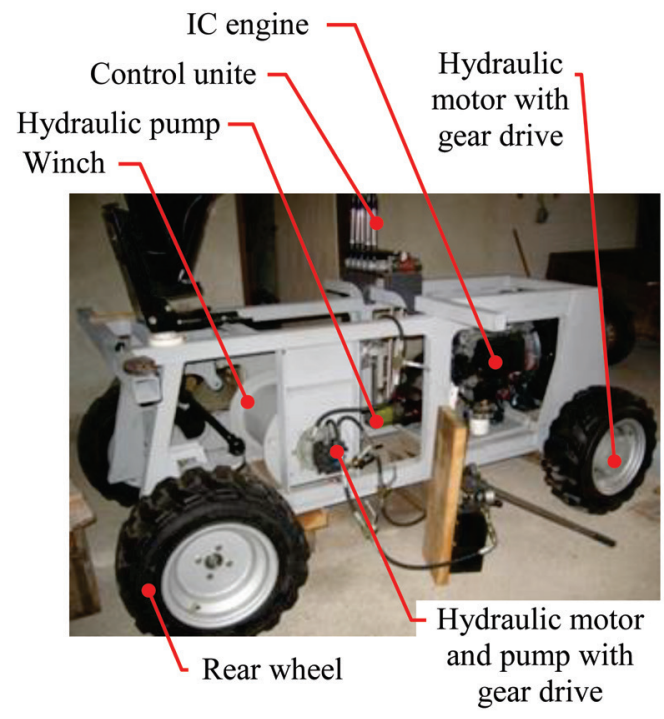

Fig. 6. Prototyping the EH machine
Since this machine is self-propelling, it has a significantly wider scope than ordinary winch carts with accessories only and no self-drive system. The next obvious advantage of the new EH machine is its ability to use both systems of the drive: the wheels and winch. No additional tractor is required for coming up steep terrains. Even though the new EH machine has a dual drive is suitable due to the low weight carrying out the common farm work on nearly flat terrains.

The new EH machine is conceived in real and prototyped already to the final stage, equipped with all components, Fig. 6.

The new EH machine is equipped with the rope winch at its rear. The rope is firmly anchored on the top of the terrain. With the upwards movement of the hydraulic machine, both drive systems (wheels and winch) function simultaneously. In the case of bad wheel grip due to the slippery terrain, the smart control system redirects the power to the winch drive.

In the case of terrain/rope contact, as presented in Fig. 7, the rope will no harm the terrain because it is not moving along its length. In comparison to the winch cart with the winch on the top of the terrain, this is likely a significant improvement. To avoid unnecessary friction, the rope is released as it is needed.

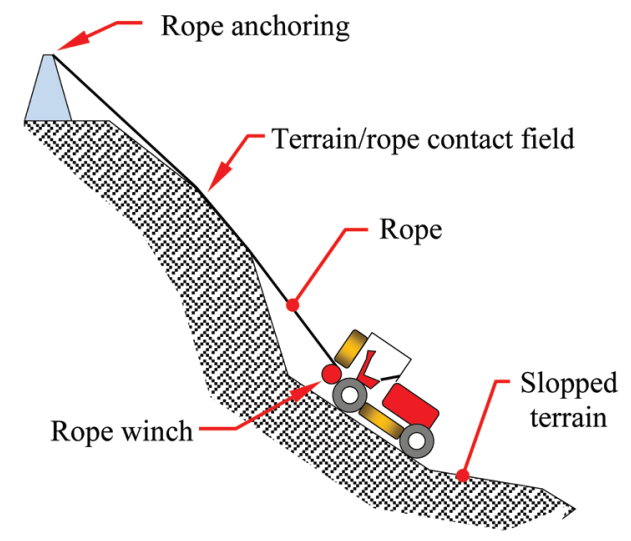

Fig. 7. Terrain/rope contact situation

To run both accessories, the sprayer and mower, the new EH machine has two built-in output drives: one is positioned on the front and the other on the rear of the vehicles. Two output drives ensure simultaneous but independent use of both accessories. The energy for one accessory comes directly from the IC engine, but the other accessory can obtain the necessary energy from the potential energy of the new EH machine traveling downhill. When the vehicle is moving downhill, both accessories can be active. When it is moving uphill, both accessories are 
excluded, and all the IC engine power for moving the vehicle is available.

Using the potential energy, that is coming from the descending new EH machine for powering the accessories, saves time and energy. If the potential energy does not cover the needs of accessories, additional energy comes from the IC engine.

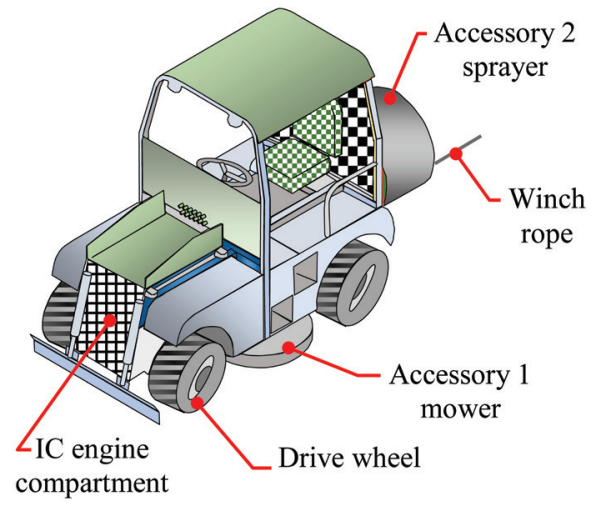

Fig. 8. The new EH machine

In Fig. 8, the new EH machine is presented. The main advantage of it is the free flow of the energy. Both the IC engine and winch rope can become a source of power that can run the accessories. The hydraulic pump on the winch can transform the potential energy of the descending machine into the pressure and flow of the hydraulic oil, which are directly used for running the accessories.

\subsection{Portable Flatbed Design}

To move the new EH machine from one crop line to the next, a self-propelled portable flatbed is provided that would be attached to the anchor line. Therefore no additional tractor is required to do this work.

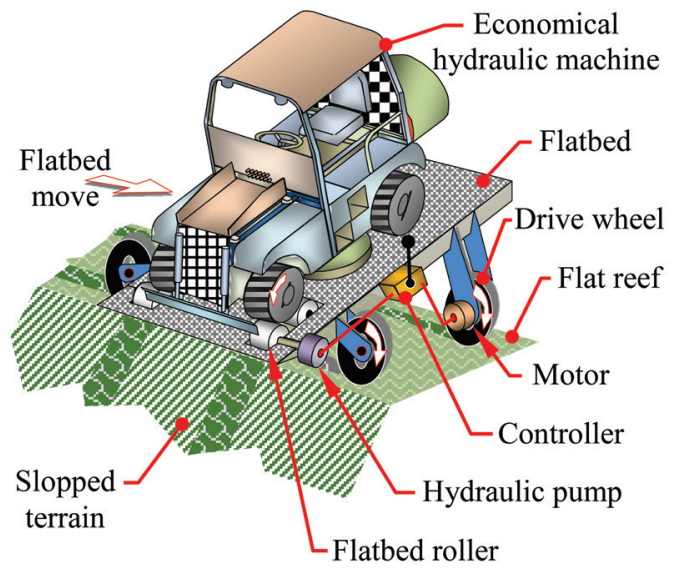

Fig. 9. Working portable flatbed
After the new EH machine is on the portable flatbed, Fig. 9, the vehicle front wheels are in contact with the driving rollers of the flatbed. The rollers drive the system that hydraulically moves the portable flatbed along the flat reef of the terrain [26].

\section{EFFICIENCY OF THE NEW ECONOMICAL HYDRAULIC MACHINE}

Sample calculations are done for one hectare of terrain, on which 24 treatments are considered. The treatments are 10 times of mowing, 10 times of spraying, one -time of scoring, one -time of fertilizing, one -time of peak cutting and one -time of harvesting crops.

\subsection{Constant Sloped Terrain}

The slopes of the terrain are chosen $0 \%, 35 \%, 60 \%$ and $100 \%$. For the steeped slope the new EH machine is used with added technology for using the potential energy, which enables merging two treatments, such as mowing and spraying. That fact leads to the reduction of the number of the vehicle drives per year, from 24 to 14 with the use of the new EH machine on the $100 \%$ slope.

The labour time for using the new EH machine is $20 \%$ longer than for the treatments on the other slopes due to the four treatments in which the winch tractor should not move along the terrain when the vehicle is at the bottom of the terrain. For the treatments of the first three slopes, a standard tractor, which can simply turn around at the end of each column, is assumed. In comparison with Table 3, in Table 4 only the fourth column is different. Instead of the cart the new EH machine is analyzed. The fuel consumption of this machine is only slightly higher comparing with the tractors which process nearly flat farm fields.

Table 4. Data for treatment one hectare of agricultural terrain per year with all accessories

\begin{tabular}{lcccc}
\hline Machine & \multicolumn{3}{c}{$\begin{array}{c}\text { Common or } \\
\text { caterpillar tractor }\end{array}$} & $\begin{array}{c}\text { New EH } \\
\text { machine }\end{array}$ \\
\hline Terrain slope [\%] & 0 & 35 & 60 & 100 \\
\hline Energy for treating [MJ] & 1458 & 1488 & 1535 & 1763 \\
\hline Fuel [l] & 121 & 123 & 127 & 146 \\
\hline $\mathrm{CO}_{2}$ emission [kg] & 313 & 319 & 329 & 386 \\
\hline Labour time [h] & 30 & 30 & 30 & 35 \\
\hline Efficiency [\%] & 62 & 61 & 59 & 51 \\
\hline
\end{tabular}


In Table 5, the use of a winch cart and the newly designed $\mathrm{EH}$ machine are compared for very steep terrain $(100 \%)$.

Table 5. Treatment of one hectare $100 \%$ slope terrain per year with all accessories

\begin{tabular}{lcc}
\hline & Winch cart & New EH machine \\
\hline Total Energy [MJ] & 2971 & 1763 \\
\hline Total Fuel [l] & 247 & 146 \\
\hline $\mathrm{CO}_{2}$ emission $[\mathrm{kg}]$ & 651 & 386 \\
\hline Labour time [h] & 60 & 35 \\
\hline Efficiency [\%] & 30 & 51 \\
\hline
\end{tabular}

The efficiency of the crop treatment is calculated according to the equation:

$$
\eta=\frac{W_{a c c}}{W_{\text {acc }}+W_{\text {trac }}},
$$

where $\eta$ is efficiency of the crop treatment, $W_{\text {acc }}$; energy needed for the accessories; and $W_{\text {trac }}$; energy needed for the machine drive.

Fuel consumption is calculated with the equation:

$$
Q_{\text {Fuel }}=\frac{W_{\text {Total }}}{c} \cdot \frac{1}{\eta_{I C}},
$$

where $Q_{\text {Fuel }}$ is total fuel used, $W_{\text {Total }}$ total energy used, $c=41.2 \mathrm{MJ} / \mathrm{kg}$ heating value of fuel [27], and $\eta_{I C}=0.35$ efficiency of internal combustion engine [2].

Carbon dioxide emission is calculated with the equation:

$$
\mathrm{CO} 2_{\text {emiss }}=f_{\mathrm{CO2}} \cdot Q_{\text {Fuel }} \text {, }
$$

where $\mathrm{CO} 2_{\text {emiss }}[\mathrm{kg}]$ is carbon dioxide emission, and $f_{\mathrm{CO} 2}=3.16$ carbon dioxide emission coefficient [28].

According to the Table 5 all advantages are on the side of the newly developed EH machine, especially the efficiency of the crop treatment, which is $70 \%$ better comparing with the common cart driven by winch. Above statements are additional confirmed with the procedure based on the neural networks [29] to [31], which is specially designed to predict crop treatment efficiency, fuel consumption, the level of $\mathrm{CO}_{2}$ emissions and the time taken for the treatment of agricultural land [26].

\subsection{Squared Terrain with Realistic Topography}

In the preliminary subchapter, the constant slope of the whole terrain is assumed. To describe the agriculture terrain on which crops can be found in real circumstances, a matrix is made for which the individual slopes of increments are specified. The terrain is simplified by considering the following assumptions:

- the outer border of the terrain is square with sides $100 \mathrm{~m}$ long.

- each stroke is $100 \mathrm{~m}$ long.

- the distance between the crop columns is assumed to be $2 \mathrm{~m}$. Therefore, 50 strokes are needed to treat the whole terrain.

- each stroke is divided into ten segments of slope. The slope of the individual segment is an independent data point and represents the average. This characteristic is represented by one column in the matrix.

- the matrix that describes such terrain consists of 10 rows and 50 columns.

The very likely matrix of the realistic topography could look like this:

$$
\mathbf{M}_{\text {Slope }}=\left[\begin{array}{rrrrr}
44 & 43 & & 33 & 32 \\
44 & 43 & & 32 & 32 \\
43 & 43 & \ldots & 31 & 31 \\
42 & 42 & & 30 & 30 \\
42 & 41 & & 30 & 29 \\
41 & 41 & & 29 & 28 \\
41 & 41 & & 29 & 28 \\
41 & 40 & \ldots & 27 & 27 \\
40 & 39 & & 27 & 27 \\
38 & 38 & & 27 & 27
\end{array}\right] .
$$

Each number in the matrix represents the segment slope in degrees. The terrain specified in the matrix is presented in Fig. 10.

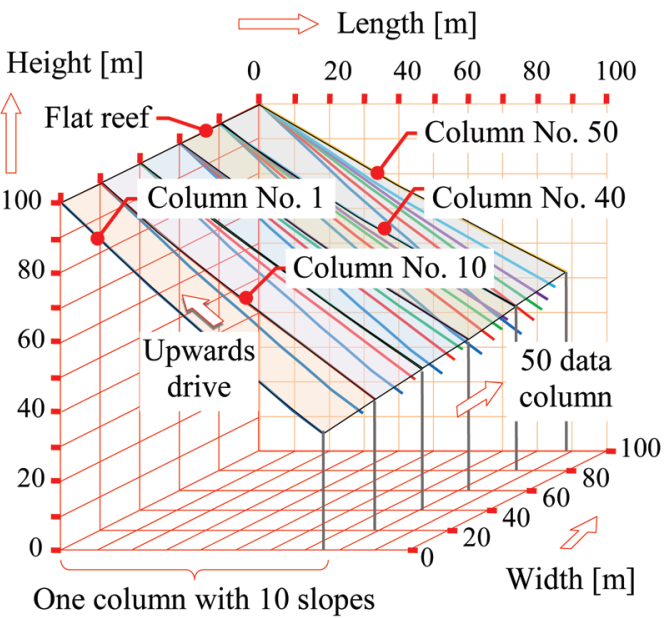

Fig. 10. Presentation of the one hectare of terrain with realistic topography 
Driving resistances are calculated according to the following two equations:

$$
\begin{gathered}
R_{f}=f_{r} \cdot\left(m_{T}+m_{D}+m_{M}+m_{S}\right) \cdot \cos \alpha_{m, n} \cdot g, \\
R_{S}=\left(m_{T}+m_{D}+m_{M}+m_{S}\right) \cdot \sin \alpha_{m, n} \cdot g,
\end{gathered}
$$

where $R_{f}$ is rolling resistance for segment $s_{m, n} ; R_{S}$ slope resistance for segment $s_{m, n} ; \alpha_{m, n}$ slope of the segment $s_{m, n} ; s_{m, n}$ segment in row $m=1$ to 10 and column $n=$ 1 to 50 .

The total resistance that acts during the moving of the vehicle equipped with two accessories upwards the sloped terrain is the sum of rolling and slope resistances. The applicable resistance that acts during the moving the same vehicle downwards is the difference of those individual resistances that are described with the equations:

$$
\begin{gathered}
R_{u p}=R_{S}+R_{f}, \\
R_{\text {down }}=R_{S}-R_{f},
\end{gathered}
$$

where $R_{u p}$ is applicable resistance at upwards drive and $R_{\text {down }}$ applicable resistance at downwards drive.

To obtain the consumed energies needed to overcome a sloped segment up- or down-wards, the resistances are multiplied by the length of the segment that is $c=10 \mathrm{~m}$ because of the simplicity introduced.

$$
\begin{gathered}
W_{u p}=R_{u p} \cdot c, \\
W_{\text {down }}=R_{\text {down }} \cdot c,
\end{gathered}
$$

where $W_{u p}$ is applicable energy at upwards drive, and $W_{\text {down }}$ an applicable energy at downwards drive.

The total time, $t_{\text {total }}$, needed for the one treatment of the agricultural terrain is calculated with the equation:

$$
t_{\text {total }}=\frac{2 \cdot 50 \cdot 100 \cdot \mathrm{m}}{v_{a v}} .
$$

The numeral 2 represents the number of vehicle strokes for each line of crops. The numeral 50 is equivalent to the crop lines or number of columns; $100 \mathrm{~m}$ is the terrain length of the crop column, Fig. 10.

The number of accessories, one or two, that can be functioning during the vehicle's downward drive, depends on the vehicle type. With the respect to the fact that the tractor power is very close to the minimum needed for the drive upwards, only one accessory can be used in case of the vehicle descending. In the case of a machine that can exploit the available potential energy, two accessories can be active simultaneously.

Technology that would be able to transform the potential energy for running the accessories cannot be derived mechanically for many reasons. The obvious one is the incorrect ratio between the wheels and accessories. A gearbox that would change this ratio freely would be necessary. The only way to accomplish this in financially feasible manner is the introduction of a hydraulic transmission. This has to be modified for this situation. In the continuation, two hydraulic agricultural machines are considered; the first one with only a basic hydraulic and the second one, called new EH machine, which is modified. Only the latter machine enables the simultaneous use of both accessories.

In Tables 6 and 7, data are presented that enable estimating the type of the machine. The data collected in the Table 6 describe the situation on one hectare of terrain treatment with two accessories only. The data in Table 7 represent the situation over the year.

The data in the Tables 6 and 7 are calculated on the basis of slopes delivered in $\mathbf{M}_{\text {Slope }}$ matrix and by using already explained equations (from 1 to 17).

Table 6. Data for treating one hectare of real agricultural terrain per year - two accessories

\begin{tabular}{lcc}
\hline & Winch cart & New EH machine \\
\hline Energy for treating $[\mathrm{MJ}]$ & 2310 & 1388 \\
\hline Fuel $[\mathrm{l}]$ & 192 & 115 \\
\hline $\mathrm{CO}_{2}$ emission $[\mathrm{kg}]$ & 506 & 304 \\
\hline Labour time $[\mathrm{h}]$ & 50 & 25 \\
\hline Efficiency [\%] & 35 & 58 \\
\hline
\end{tabular}

Table 7. Treatment of one hectare of real agricultural terrain per year - all accessories

\begin{tabular}{lcc}
\hline & Winch cart & New EH machine \\
\hline Total Energy [MJ] & 2729 & 1743 \\
\hline Total Fuel [l] & 227 & 145 \\
\hline $\mathrm{CO}_{2}$ emission $[\mathrm{kg}]$ & 598 & 382 \\
\hline Labour time [h] & 60 & 35 \\
\hline Efficiency [\%] & 33 & 52 \\
\hline
\end{tabular}

On the basis of the data in the previous two tables, it can be concluded that the new EH machine with modified hydraulic transmission demonstrates some obvious advantages. The savings in energy, fuel, emission and consumed labour time are obvious and doubtless cover the higher expenses of purchasing the equipment.

\section{ESTIMATING THE TERRAIN FOR NEW ECONOMICAL HYDRAULIC MACHINE APPLICABILITY}

The nominal power of the EH machine should be as low as possible. First condition: the new EH machine equipped with the heaviest accessories should be 
driven upwards with the speed of about $4 \mathrm{~km}$ per hour. Second condition: when descending, the EH machine should have enough power to overcome the driving resistances and to run the two accessories. When descending the $\mathrm{EH}$ machine is using the energy of the IC engine and the potential energy.

A critical situation would occur at the moment the total power would not be enough to run both accessories at their maximum power. From the known data about the IC engine power, accessories' power, and other necessary data from the machines, only the driving resistance is questionable. In the case of an agriculture vehicle, the driving resistance directly depends on the terrain slope.

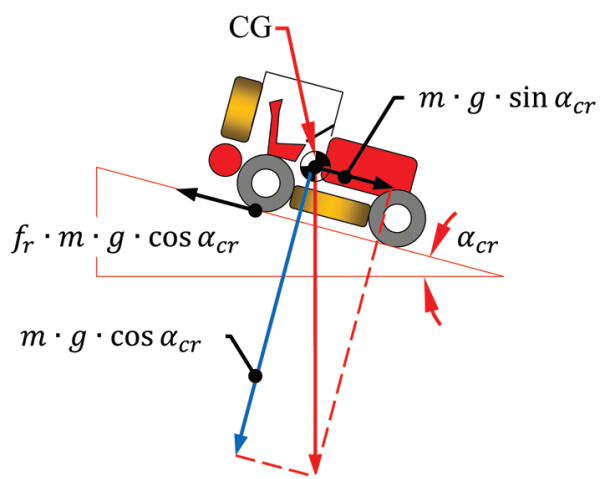

Fig. 11. Force equilibrium at critical slope determination

To fulfil the second condition with the lowest power of the IC engine, the rolling resistance should be equal to the gravity acting along the slope direction, Fig. 11. The calculation of the critical slope, $\alpha_{c r}$, is done as follows:

$$
\begin{gathered}
m \cdot g \cdot \sin \alpha_{c r}=f_{r} \cdot m \cdot g \cdot \cos \alpha_{c r}, \\
m=m_{T}+m_{D}+m_{m u}+m_{S p},
\end{gathered}
$$

where $m$ is total mass of $\mathrm{EH}$ machine, $f_{r}=0.25$ rolling resistance coefficient [14], and $\alpha_{c r}$ critical slope.

From the above equation, it is derived that:

$$
\alpha_{c r}=\tan ^{-1} f_{r} .
$$

Considering the supposed rolling resistance in its value, the critical slope is: $\alpha_{c r}=14^{\circ}$.

Once the critical slope is determined, the terrain topography can be judged, Fig. 12. The only constraint to be considered is that each slope should be greater than a critical one.

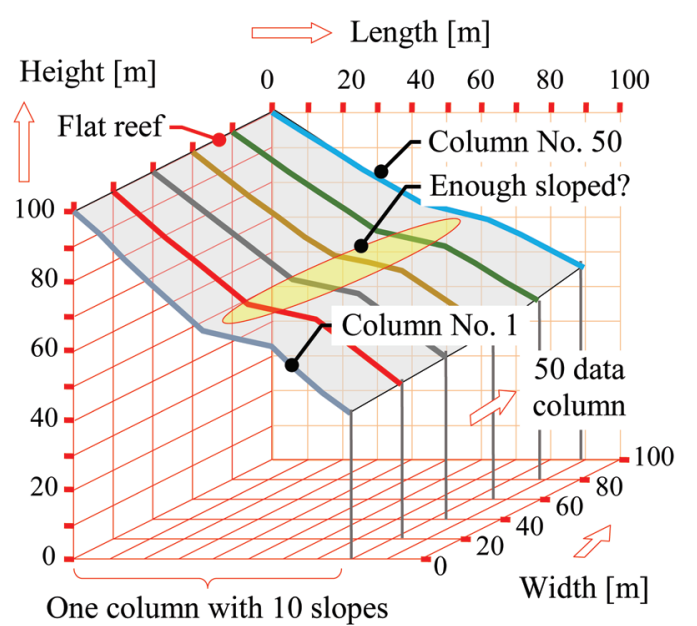

Fig. 12. Presentation of one hectare of terrain with the topography, which is perhaps locally not sufficiently sloped

Another representation of the terrain can be made with the matrix of partial slopes.

$$
\mathbf{M}_{\text {Slope }}=\left[\begin{array}{rrrrr}
44 & 43 & & 33 & 32 \\
44 & 43 & & 32 & 32 \\
43 & 43 & \ldots & 31 & 31 \\
42 & 42 & & 30 & 30 \\
42 & 41 & & 30 & 29 \\
14 & 14 & & 14 & 14 \\
14 & 14 & & 14 & 14 \\
41 & 40 & \ldots & 27 & 27 \\
40 & 39 & & 27 & 27 \\
38 & 38 & & 27 & 27
\end{array}\right] .
$$

The intention of the calculation of energy, the power and the time consumption on the terrain, as presented in Table 8, is to verify the IC engine power, which should not be too low.

Table 8. Data for treating one hectare of realistic agricultural terrain (strip with limited slope in the middle of terrain)

\begin{tabular}{lcc}
\hline & $\begin{array}{c}\text { Two accessories } \\
\text { 1 treatment }\end{array}$ & $\begin{array}{c}\text { All accessories } \\
\text { 24 treatments }\end{array}$ \\
\hline Energy for treating [MJ] & 137 & 1719 \\
\hline Fuel [l] & 11 & 142 \\
\hline $\mathrm{CO}_{2}$ emission $[\mathrm{kg}]$ & 30 & 377 \\
\hline Labour time $[\mathrm{h}]$ & 2.5 & 35 \\
\hline Efficiency $[\%]$ & 59 & 53 \\
\hline
\end{tabular}

In case the slope of the particular segments on the terrain are too flat, the IC engine power will not be sufficient to run the accessories at full power while running the machine itself. In this case the IC 
engine power should be increased to an extent that the engine is then able to run the accessories. In addition to the gravity force, which is acting along the slope, the driving force should be added, which is generated on the wheel circumferential. The sum of these forces should be in equilibrium with the rolling resistance:

$$
m \cdot g \cdot \sin \alpha+\frac{\Delta P}{v_{a v}}=f_{r} \cdot m \cdot g \cdot \cos \alpha
$$

$\Delta P$ is IC engine power (excess over accessories needs), $\alpha$ actual minimum slope, and $v_{a v}[\mathrm{~m} / \mathrm{s}]$ average velocity of the machine.

From the Eq. (21) the IC engine power surplus can be derived:

$$
\Delta P=m \cdot g \cdot v_{a v} \cdot\left(f_{r} \cdot \cos \alpha-\sin \alpha\right) .
$$

The power of the selected IC engine of the EH machine must be the same or greater than the power that is required to run the accessories and the machine downwards at the most flat terrain section where the minimal gravity force is acting.

\section{CONCLUSIONS}

In this article, the initial hypothesis about the possibility of the energy saving of the agricultural winch machine is confirmed. The problem of using the efficient potential energy in the working process cannot be carried out with the normal mechanical transmission, because each of the accessories needs their own input velocity and torque. As a result, the hydraulic transmission is the only rational way to effectively use the potential energy, which is available in abnormal quantities on this type of agriculture terrain. For the real terrain is proven the rise of the crop treatment efficiency per year from the normally $0.33 \%$ to $0.52 \%$ that is characteristic of the new EH machine. At the same time the labor time is shortened from 60 hours to 35 hours only.

The designer of the new EH machine defends the use of the IC engine with the minimal power due to minimal machine weight, minimal environmental burdens, and as low as possible expenses. A few purely theoretical calculations where the new EH machine and the potential competitors are compared on the ideal terrain to emphasize the eligibility of the proposed new machine. According to the analysis, the use of the common winch cart that is widely in use around the world seems to be non-economical and not rational.

\section{REFERENCES}

[1] Jerončič, R., Bernik, R. (2008). The Research of the number of accidents with the agriculture and forestry tractors in the Europe and the main reasons for those accidents. Strojniški vestnik - Journal of Mechanical Engineering, vol. 54, no. 7-8, p. 557-564.

[2] Bernik, R. (2004). Techniques in Agriculture. University of Ljubljana, Biotechnical Faculty, Ljubljana (in Slovene)

[3] Vidoni, R., Bietresato, M., Gasparetto, A., Mazetto, F. (2015). Evaluation and stability comparsion of different vehicle configurations for robotic agricultural operations on side slopes. Biosystems Engineering, vol. 129, p. 197-211, D0I:10.1016/j.biosystemseng.2014.10.003.

[4] Oswald, W. (2000). Taschenbuch der Weinbautechnik. Fachverlag Dr. Fraund, Mainz.

[5] Bohme, A. (2003). Umweltgerechte Technik den Steillagenweinbau. KTBL, Darmstadt.

[6] Uberti, S., Gadola, M., Chindamo, D., Romano, M., Galli, F. (2015). Design of a double wishbone front suspension for an orchard-vineyard tractor: Kinematic analysis. Journal of Terramechanics, vol 57, p. 23-39, D0l:10.1016/j. jterra.2014.11.001.

[7] Rühling, W. (1991). Mechanisierung von Steillagen auf der Basis handgeführter Kleinraupen. Der Deutsche Weinbau, no. 16, p. 631-638.

[8] Bartsch, M. (2013). New machine could save German vineyards, from http://www.spiegel.de/international/ germany/steeply-sloped-german-vineyards-hope-technologycan-save-them-a-935752.html, accessed on 2016-11-10.

[9] Mashadi, B., Hanif, H. (2009). Automatic control of a modified tractor to work on steep side slopes. Journal of Terramechanics, vol. 46, no. 6, p. 299-311, D0l:10.1016/j. jterra.2009.08.006.

[10] Wild, K., Auernhammer, H. (1996). Ansätze zur automatisierten Arbeitszeitermittlung bei Feldarbeiten. Landtechnik, vol. 51, no. 4, , p. 198-199, DOl:10.15150/It.1996.2771

[11] Jäger, P. (1991). Zeitbedarf von Feldarbeiten. Landtechnik, vol. 46, no. 4, p. 69-71.

[12] Hrastar, K. (2014). Tractor Catalogue: Handbook. ČZD Kmečki glas. Ljubljana (in Slovene).

[13] Zupan Catalog (2016). from htpp://www.zupan.si, accessed on 2016-11-10

[14] Saarilahti, M. (2002). Soil Interaction Model. MSc thesis, University of Helsinki, Helsinki.

[15] FITO-INFO Catalog (2016). from http:///www.fito-info.si, accessed on 2016-11-10.

[16] INO Brežice Catalog (2016). from http://www.inobrezice.com, accessed on 2016-11-10.

[17] Fabijan Catalog (2016). from http://www.fabijan.si, accessed on 2016-11-10.

[18] KGM-Podlehnik Catalog (2016). from http://kmg-podlehnik.si, accessed on 2016-11-10

[19] Katrašnik, T., Trenc, F., Oprešnik, S. (2007). Study of the energy-conversion efficiency of hybrid powertrains. Strojniški vestnik - Journal of Mechanical Engineering, vol. 53, no.10, p. 667-682. 
[20] Hunt, D. (1995). Farm Power and Machinery Management. lowa State University, Arnes, p. 259-275.

[21] Flašker, J., Pehan, S. (2005). Power Transmissions. University of Maribor, Faculty of Mechanical Engineering, Maribor. (in Slovene)

[22] Flašker, J., Pehan, S. (2008). Tribology. University of Maribor, Faculty of Mechanical Engineering, Maribor, Maribor. (in Slovene)

[23] Eggert, J. (2005). Engineering Design, Prentice Hall, New Jersey.

[24] Bižal, A., Klemenc, J., Fajdiga, M. (2014). Evaluating the statistical significance of a fatigue-life reduction due to macro-porosity. Strojniški vestnik - Journal of Mechanical Engineering, vol. 60, no. 6, p. 407-416, D0l:10.5545/svjme.2013.1453.

[25] Zaletelj, H., Fajdiga, G., Nagode, M. (2011). Numerical methods for TMF cycle modeling. Strojniški vestnik - Journal of Mechanical Engineering, vol. 57, no. 6, p. 485-494, DOI:10.5545/sv-jme.2010.212.

[26] Kodrič, M. (2016). Development of a Hybrid Machine for Working on Sloping Terrain, PhD Thesis, University of Maribor, Faculty of Mechanical Engineering, Maribor. (in Slovene)

[27] Kraut, B. (1987). Mechanical Engineering Handbook. Tehniška založba Slovenije, Ljubljana. (in Slovene)

[28] Ecoscore Catalog (2016). from http://www.ecoscore.be, accessed on 2016-11-10.

[29] Hykin, S. (1994). Neural Networks, a Comprehensive Foundation. MacMillan College New York.

[30] Bishop, C.M. (1995). Neural Networks for Pattern Recognition. Clarendon Press, 0xford.

[31] Rahimi-Ajdadi, F., Abbaspour-Gilandeh, Y. (2011). Artificial Neural Network and stepwise multiple range regression methods for prediction of tractor fuel consumption. Measurement, vol. 44, no. 10, p. 2104-2111, D0I:10.1016/j. measurement.2011.08.006. 